\title{
The Relative Contribution of Mindfulness and Gratitude in Predicting Happiness among University Students
}

\author{
Aljawharh Ibrahim Alsukah \\ Associate Professor, \\ Department of Psychology, \\ College of Education, \\ Princess Nourah bint Abdulrahman University, \\ Saudi Arabia

\section{Shaimaa Ezzat Basha} \\ Associate Professor, \\ Department of Psychology, \\ College of Education, \\ Princess Nourah bint Abdulrahman University, \\ Saudi Arabia; \\ Faculty of Arts, Helwan University, Egypt
}

DOI: https://doi.org/10.36941/jesr-2021-0097

\begin{abstract}
The present study aims at identifying the separate and interactive contribution of gratitude and mindfulness in predicting happiness; examining the relationship between these variables; identifying differences between students with high happiness and students with low happiness in gratitude and mindfulness; and identifying the levels of gratitude, mindfulness, and happiness among the students of Princess Nourah Bint Abdulrahman University. The research sample consisted of 447 female students aged 18-25 years. The research instruments included the Toronto Mindfulness Scale, the Oxford Happiness Questionnaire, as well as the Gratitude, Resentment, and Appreciation Test-Short form. The study found out that gratitude and mindfulness had a significant contribution in predicting happiness among university students (31\% and $41.5 \%$, respectively). The interaction between the total scores of mindfulness and gratitude contributed $51.5 \%$ of the variance in happiness among university students. The interaction between mindfulness, sense of abundance, and simple appreciation contributed $54.4 \%$ of the variance in happiness among university students. The study found a positive correlation between mindfulness, gratitude (sense of abundance, simple appreciation, appreciation of others), and happiness. Additionally, it was found that students at Nourah Bint Abdulrahman University had moderate levels of mindfulness and moderate to high levels of gratitude and happiness. The sense of abundance domain was moderate, the simple appreciation domain was high, and the appreciation of others domain was moderate. Mindfulness, gratitude, sense of abundance, simple appreciation, and appreciation of others increased among the students with high happiness.
\end{abstract}

Keywords: Gratitude, Sense of abundance, Mindfulness, Happiness, University students 


\section{Introduction}

Based on the Saudi Vision 2030 and enhancing a healthy lifestyle according to the Quality of life program 2020, Princess Nourah Bint Abdulrahman University seeks to enhance the psychological health and university life quality of its students through the Happiness, Positivity, and University Life Quality Enhancement Initiative among the university's affiliates. It creates a positive and happy university environment that takes "happiness means productivity and change" as a slogan and endorses benevolence, satisfaction, and gratitude as its values. Therefore, Princess Nourah Bint Abdulrahman University's administration is keen to observe the real levels of happiness, positivity, mindfulness, and gratitude among its students. Additionally, the Healthy Cities Program in the Ministry of Health coordinated a consultative meeting with the World Health Organization team and Nourah Health team represented by the program's mental health committee to discuss the establishment of a mental health observatory and to develop a strategy for promoting the students' health (@PNU_Live, 2020).

The present study aims at identifying the levels of gratitude, mindfulness, and happiness among Princess Nourah Bint Abdulrahman University students. It also aims at identifying the separate and interactive contribution of gratitude (emotional) and mindfulness (cognitive) in predicting happiness among university students; examining the relationships between these variables; defining differences between students with high happiness and students with low happiness in gratitude and mindfulness. This topic falls within the domain of positive psychology.

Happiness falls under the umbrella of positive psychology, which argues that the individual has internal strengths and weaknesses that determine one's life (AlAbdaely, 2018). It is defined as a state of internal equilibrium accompanied by several positive emotions, such as satisfaction, joy, and pleasure, which are connected to life's core aspects, e.g., social relationships, family, and work (Al-Enzi, 2001). A happy individual has positive energy and tends to be more active, passionate, and lively compared to less happy individuals (Csikszentmihalyi and Hunter, 2003).

Seligman, Steen, Park, and Peterson (2005) focus on psychological interventions that increase one's happiness and make life more meaningful. They gave an overarching vision to reach sustainable happiness that includes psychological well-being. This step was the first in developing a real happiness theory into the Well-being Theory. Well-being can be explained through two general perspectives: The hedonic approach focuses on happiness and defines well-being in terms of attaining pleasure and avoiding pain, whereas the eudaimonic approach emphasizes meaning and self-awareness and determines well-being in terms of the level one fully functions with (Ryan and Deci, 2001).

According to the Broaden-and-Build Theory, positive emotions broaden people's thinking and allow them to build psychological, intellectual, and social resources. Positive emotions, especially gratitude, may also play a role in stimulating individuals' engagement in positive behaviors that leads to their improvement (Armenta, Fritz, and Lyubomirsky, 2017). It was shown that grateful thinking improves the individual's temperament (Watkins, Woodward, Stone, and Kolts, 2003).

In this regard, Safaria (2014) found out that gratitude was the most predictive variable of happiness among university students as it was rated $58 \%$. Gratitude can be defined as a feeling of thankfulness and appreciation of a benefit one receives. Trait gratitude is the tendency to experience this state (Basha and AbdAlstr, 2015; Watkins et al., 2003). Gratitude includes a sense of abundance (SOA), which refers to the absence of feeling deprived and a general appreciation of life in general; appreciation of others (AO) as the feeling of others' contribution to one's achievements or well-being; and simple appreciation (SA) or the ability to appreciate or think about small things; full awareness of the present moment, and admiration of nature, beauty or life (Simons et al., 2020).

Thus, happiness can be understood as an emotion that was developed to stimulate individuals to move towards stimuli that facilitate survival or reproductive success. Gratitude developed with respect to our strong tendencies toward mutual altruism, which helps individuals stay in positive contact with others in small social groups (Geher and Wedberg, 2019).

Gratitude is a moral emotion equal to other moral emotions such as empathy and guilt. Individuals typically experience gratitude when they feel the benevolent acted to enhance their 
psychological well-being. Thus, gratitude can be illustrated as a moral barometer - a response to others' noble manners. Gratitude drives beneficiaries to participate in pro-social behavior (moral motive). Also when one's gratitude is expressed to the benevolent, it motivates the benevolent to act in a more prosocial manner in the future (moral incentive) (Basha and AbdAlstar, 2015; Froh et al., 2011; McCullough, Kilpatrick, Emmons, and Larson, 2001).

Measuring and developing happiness, mindfulness, and gratitude among the youth is important for several reasons, including association with positive emotional functioning (Froh et al., 2011). In other words, a happy person is young, healthy, open-minded, optimistic, married with great selfesteem, functional morale, free of anxiety, and religious with modest requirements, of either gender (Diener, Suh, Lucas, and Smith, 1999). Peterson, Ruch, Beermann, Park, and Seligman (2007) pointed out that gratitude was the strongest predictor of life satisfaction in an American sample. Additionally, the therapeutic interventions based on mindfulness and gratitude are effective in limiting depression and tension and increasing happiness (Leary, 2015). Mindfulness is linked to better mental health, the ability to self-soothe when feeling upset, resilient responses to distress, and awareness of one's emotional state (Basha, 2018).

Mindfulness can be defined as the ability to listen and become aware without making judgments or avoidance in the present moment (Brown and Ryan, 2008). It is also a targeted specific concern at the present moment free of prejudice and judgments (Fakhri, Bahar, and Amini, 2017). Mindfulness is significantly correlated to gratitude, and both gratitude and perceived support mediate the relationship between mindfulness and mood (Swickert et al., 2019).

Four mindfulness skills can be taught or practiced: (1) mindful description, or the experiential expression of observations without judgment or conceptual analysis; (2) mindful observation, which means the careful attention to internal and external phenomena, such as ideas, scents, or deep feelings; (3) act with awareness, which refers to the full engagement of undivided attention in a current activity without judgments; (4) non-judgmental acceptance, which means that the individual should not evaluate his/her experiences at the present moment (Basha and AbdAlstar, 2015; Dekeyser, Raes, Leijssen, Leysen, and Dewulf, 2008). The theoretical explanations highlight cognitive, attentive, and behavioral resilience as components and results of mindfulness. The opposite pattern endorsing a narrow perspective and automatic, habitual, and rigid response is linked to poor problem solving and more distress (Basha, 2018; Feldman, Hayes, Kumar, Greeson, and Laurenceau, 2007).

Mindfulness can be explained in terms of the reassessment of the meaning model. Individuals have a global internal framework of meaning that consists of their values, beliefs, and rooted patterns in viewing the world. This resembles Piaget's scheme concept, which is the core of his cognitive development theory. The individuals' global framework of meaning forms how they explain life experiences when situations occur. Thus, individuals are in a constant state of assessing meanings, matching the situational meaning to their global meaning framework (Bellin, 2015). Mindfulness is also a form of meditation, which is linked to emotional processing. Meditation in practice means making something familiar. Focusing on meditation practices is becoming more aware, familiar, and reflective in one's mental processes (Basha, 2018; Gilbert et al., 2019). Brown and Ryan (2003) found high correlations between mindful attention awareness and self-esteem.

In this regard, individuals reporting low levels of mindfulness are more vulnerable to higher levels of internal symptoms, while lower levels of gratitude are connected to higher depression symptoms (Duprey, McKee, O'Neal, and Algoe, 2018). Swain et al. (2020) offered support in their empirical study to both gratitude and mindfulness as suitable interventions for physical health conditions and showed how they could be used together. Fuller-Tyszkiewicz et al., 2019) reported that the intervention group had access to an e-health platform that contained a series of brief video activities (e.g. gratitude, breathing, and relaxation tasks) that were shown in previous studies to improve body satisfaction. The study found greater improvement in body satisfaction after the intervention in the intervention group. The use of the intervention content was linked to instant increases in body satisfaction evaluations similar to the case. The size of improvement in the present moment was predictive of greater improvement in post-intervention symptoms and maintaining it. 
The aforementioned review shows that mindfulness and gratitude may play an important role in attaining individuals' happiness and psychological well-being. Therefore, this study primarily seeks to identify the separate and interactive contribution of gratitude (emotional) and mindfulness (cognitive) in predicting happiness among university students; and examine the relationships between these variables. It also aims to identify the level of gratitude, mindfulness, and happiness among university students. It identifies differences between students with high happiness and those with low happiness in gratitude and mindfulness.

\section{Objectives}

Thus, the empirical objectives of the study are:

- Evaluating the level of mindfulness, gratitude, and happiness among university students.

- Examining the relationship between gratitude, mindfulness, and happiness among university students.

- Identifying the separate and interactive contribution of gratitude and mindfulness in predicting happiness among university students.

- Examining the differences between students with high happiness and students with low happiness in gratitude and mindfulness.

\section{Significance}

The theoretical and applied significance of the study can be summarized, as follows:

- It found the contribution of mindfulness and gratitude to predicting happiness among university students in an attempt to understand the nature of happiness and its predictors, the contribution of interaction among these variables, and the importance of understanding the nature of happiness among university students.

- The findings of the present study can be employed in improving happiness development programs among university students.

- The scales used in the present research can be utilized in examining, diagnosing, predicting, and following-up the results of psychological rehabilitation and therapy and preventive programs.

\section{Questions}

The study seeks for answering the following questions:

1. What are the levels of gratitude, mindfulness, and happiness among university students?

2. What is the size and type of relationship between gratitude, mindfulness, and happiness among university students?

3. Does gratitude contribute to predicting happiness among university students?

4. Does mindfulness contribute to predicting happiness among university students?

5. Does the interaction between gratitude and mindfulness contribute to predicting happiness among university students?

6. How much do university students with high happiness and with low happiness vary in gratitude and mindfulness?

The relevance of the present study is due to the relevance of the studied variables, which can be detailed, as follows:

1. Mindfulness offers an alternative method to cope with negative self-thoughts by challenging their importance. Mindfulness also has an additional benefit because breathing exercises may reduce the emotional disturbance that arises during periods of non-satisfaction (FullerTyszkiewicz et al., 2019).

2. Studying gratitude is important as previous studies pointed out its importance to individuals. 
Being grateful is one of the highly-appreciated qualities (Watkins et al., 2003). Recent findings showed that mood gratitude mediates the relationship between the positive past time framework and the various psychological well-being indicators (Przepiorka et al., 2020).

3. The applied relevance of the study and a deeper understanding of the relationships between gratitude, mindfulness, and happiness is developing counseling programs or practical proposals to help university students raise their level of happiness. The findings of the study can be used in teaching university students the application of adaptive mindful strategies when they have a problem to reduce their feelings of distress.

\section{Materials and Methods}

\subsection{Method}

Since the present study aims at identifying the level of gratitude, mindfulness, and happiness among Princess Nourah Bint Abdulrahman University students, the separate and interactive contribution of gratitude and mindfulness to predicting happiness, examining the differences in mindfulness and gratitude among students with high happiness and students with low happiness, and identifying the mutual relationships among these variables, the descriptive method (both correlative and comparative) is deemed the most appropriate for the nature and objectives of the present study, as well as testing and verifying its hypotheses. This method quantitatively describes the measured phenomenon by determining the relationship between the variables.

\subsection{Sampling}

The final research sample consisted of 447 female university students aged 18 to 25 years. Table 1 details the sample's preliminary data.

Table 1: Distribution of the research sample in terms of preliminary data

\begin{tabular}{|l|l|c|c|}
\hline Variables & Category & Number & Percentage \\
\hline Marital status & Single & 410 & 91.7 \\
\hline & Married & 34 & 7.6 \\
\hline & Divorced & 3 & 0.7 \\
\hline GPA & Less than 3 & 57 & 12.8 \\
\hline & $3-4$ & 110 & 24.6 \\
\hline & $4-5$ & 280 & 62.6 \\
\hline Type of Study & College of Humanities & 176 & 39.4 \\
\hline & Scientific Colleges & 218 & 48.8 \\
\hline & Health Colleges & 53 & 11.9 \\
\hline Total & 447 & 100.0 \\
\hline
\end{tabular}

\subsection{Instruments: Psychometric properties}

The validation of instruments was conducted in a sample of 175 participants aged $18-25$ years. The data of this sample were used to verify the validity and reliability of the instruments of the present study. The present study used three main instruments, namely, the Toronto Mindfulness Scale (TMS), the Oxford Happiness Questionnaire (OHQ), and the Gratitude Resentment and Appreciation Scale (GRAT)-short form. Additionally, the researchers conducted a preliminary interview to collect data, including name, age, and other relevant data.

- The Toronto Mindfulness Scale (TMS)

The researchers applied the TMS, which was originally developed by Lau et al. 2006. The 
original scale consists of 30 items. It includes three domains: Attention, alertness, and mindful awareness. Each domain contains 10 items. The researchers reviewed the scale and ensured it was appropriate for application to the research sample. The TMS validity and reliability coefficients were calculated by applying it in an exploratory sample from the population. The final version of the scale consisted of 28 items, and a 1-4 Likert-type responses: always applies to me (4), applies to me (3); doesn't apply to me (2); never applies to me (1) for affirmative items and the reverse for negative items. Thus, the lowest score was 28 points representing a low level of mindfulness, and the highest score was 112 points representing a high level of mindfulness.

In the present study, the psychometric efficiency of the instrument was verified using internal consistency and Cronbach's alpha coefficients. With respect to internal consistency, the correlation coefficient between the item score and the domain's total score, and the correlation coefficient between the total score of each subscale and the TMS total score were calculated. The correlation coefficients of the item score and the total score of the subscale ranged from 0.30 to 0.61 , which are acceptable values. Additionally, the correlation coefficients between the subscale total score and the TMS total score ranged from 0.82 to o.85. Consequently, no items were deleted, and all the items were retained. The Cronbach's alpha coefficient was calculated for the full TMS that was 0.73 . That is, all items measured the same content.

- The Oxford Happiness Questionnaire (OHQ)

The OHQ was originally developed by Argyle, Martin, and $\mathrm{Lu}$ in 1995. The original questionnaire consisted of 29 items that measured the feelings of happiness (i.e., positive emotions, feeling in control, self-satisfaction, kindness, and sense of humor). It had a high level of validity reached using criterion validity. It also enjoyed a good level of internal consistency reliability and retest reliability. It did not have sub-domains. Abdul Khaliq developed the Arabic version with some modifications. The Arabic version consists of 29 items with five response choices. The lowest score was 29 and the highest score was 145 . The validity and reliability of the Arabic version were calculated in the Kuwaiti environment. In the present study, the authors used the OHQ applied in the Saudi environment (Jan, 2008). The final version of the scale consisted of 30 items, with a 1-4 Likert-type response, namely: absolutely applies to me (4), applies to me (3), doesn't apply to me (2); and never applies to me (1). The lowest score (30) indicates a low level of happiness, while the highest score (120) indicates a high level of happiness.

In the present study, the psychometric efficiency of the instrument was checked using internal consistency and Cronbach's alpha coefficients. The internal consistency was calculated by calculating the correlation coefficient between the item score and full-scale total score and ranged from 0.43 to 0.78 , which are acceptable values. Therefore, no items were removed and all items were retained. The scale Cronbach's alpha coefficient was calculated for the full scale and was 0.94, indicating that all items measured the same content.

- The Gratitude Resentment and Appreciation Scale (GRAT)-Short form

GRAT was originally developed by Thomas and Watkins (2003). It is based on a theory emphasizing that grateful persons have a sense of abundance, appreciate others' contributions to the quality of their life, and are ready to appreciate the small pleasures of life. They also appreciate the importance of expressing gratitude. The original scale consisted of 44 items in three domains: The sense of abundance (SOA), simple appreciation (SA), and appreciation of others $(\mathrm{AO})$. Authors prepared a short version of the original scale that consisted of 16 items covering the same domains of the original scale and has an acceptable level of reliability. Six items measured SOA, six measured SA, and four items measured AO. The GRAT-short form was used in studies in foreign settings, whereas no Arabic study used the short form of this scale. Therefore, the authors arabized it, presented it to experts to review the items after translation, then retranslated the items to check their correctness. The 
reviewers recommended eliminating an item in the SA domain as it was not suitable and vague. Thus, the final Arabic version of GRAT consisted of 15 items: 6 measured SOA, 5 measured SA, and 4 measured AO. The scale used four Likert-type responses, namely: always applies to me (4), applies to me (3), doesn't apply to me (2), and never applies to me (1). Five items are scored reversely, and 10 items are scored in the other direction. The lowest score (15 points) indicates a low level of gratitude, while the highest score (6o points) indicates a high level of gratitude.

In the present study, the psychometric efficiency of the scale was checked using internal consistency and Cronbach's alpha coefficients. With respect to internal consistency, the correlation coefficients between the item score and the total subscale score ranged from 0.51 to 0.80 , which are acceptable values. Additionally, the correlation coefficients between the subscale scores and the total score ranged from 0.27 to 0.61 , which are acceptable values. Therefore, all items were retained, and no items were removed. Cronbach's alpha coefficient was calculated for the full scale and was 0.73, indicating that all items measured the same content. Cronbach's Alpha for the SOA domain was 0.75, for the SA domain was 0.70 , and for the AO domain was 0.74 .

Table 2: Statistical description of the research sample's data in the used instruments

\begin{tabular}{|l|c|c|c|c|c|c|c|}
\hline $\begin{array}{c}\text { Statistical indicators } \\
\text { Scales }\end{array}$ & Mean & SD & Skewness & $\begin{array}{c}\text { Highest score } \\
\text { in the sample }\end{array}$ & $\begin{array}{c}\text { Lowest score } \\
\text { in the sample }\end{array}$ & $\begin{array}{c}\text { Maximum } \\
\text { score }\end{array}$ & $\begin{array}{c}\text { Minimum } \\
\text { score }\end{array}$ \\
\hline - TMS total score & 76.557 & 7.994 & -.226 & 99 & 43 & 112 & 28 \\
\hline - GRAT total score & 44.854 & 5.800 & -.345 & 57 & 25 & 60 & 15 \\
\hline - SOA & 15.711 & 3.583 & -.103 & 24 & 6 & 24 & 6 \\
\hline - SA & 17.319 & 2.474 & -1.09 & 20 & 5 & 20 & 5 \\
\hline - AO & 11.823 & 2.505 & -.302 & & 4 & 16 & 4 \\
\hline - OHQ total score & 87.733 & 14.810 & -342 & 118 & 41 & 120 & 30 \\
\hline
\end{tabular}

A value of 2.58 or more indicates skewness.

Table 2 shows the normality of distribution of participants' score to the TMS total score, GRAT total score, GRAT subscales, and OHQ total score.

\section{Results}

6.1 Hypothesis 1: Mindfulness, gratitude, and happiness among Princess Nourah Bint Abdulrahman University students are moderate.

The total score of the TMS ranged from 28 to $112(\mathrm{M}=76.56$; $\mathrm{SD}=7.99)$. The participants were divided in terms of the total TMS score into three groups: Low (28-55), moderate (56-84), and high (85-112). The results showed that most participants $(85.9 \%)$ had a moderate level of mindfulness, whereas $12.8 \%$ reported a high level of mindfulness.

The total GRAT score ranged from 15 to $60(\mathrm{M}=44.85 ; \mathrm{SD}=5.80)$. The participants were divided into three groups in terms of their GRAT total score: Low (15-29), moderate (30-45), and high (46-60). The results showed that almost half of the participants (49.9\%) reported a moderate level of gratitude, whereas the other half of the participants (49.7\%) reported a high level of gratitude. The SOA domain was moderate, $\mathrm{SA}$ was high, and $\mathrm{AO}$ was moderate.

The total OHQ score ranged from 30 to $120(\mathrm{M}=87.73$; $\mathrm{SD}=14.81)$. Accordingly, The participants were divided into three groups: Low (30-59), moderate (60-90), and high (91-120). The results indicated that $53.7 \%$ of the participants reported a moderate level of happiness, while $42.7 \%$ reported a high level of happiness. 
Table 3: The level of mindfulness, gratitude, and happiness among university students $(\mathrm{N}=447)$

\begin{tabular}{|l|c|c|c|c|c|c|}
\hline \multirow{2}{*}{ Lariables } & \multicolumn{2}{c|}{ High } & \multicolumn{2}{c|}{ Moderate } & \multicolumn{2}{c|}{ Low } \\
\cline { 2 - 7 } & Number & Percentage & Number & Percentage & Number & Percentage \\
\hline Mindfulness & 57 & $12.8 \%$ & 384 & $85.9 \%$ & 6 & $1.3 \%$ \\
\hline Gratitude total score & 222 & $49.7 \%$ & 223 & $49.9 \%$ & 2 & $0.4 \%$ \\
\hline SOA & 92 & $20.6 \%$ & 290 & $64.9 \%$ & 65 & $14.5 \%$ \\
\hline SA & 343 & $76.7 \%$ & 102 & $22.8 \%$ & 2 & $0.4 \%$ \\
\hline AO & 167 & $37.4 \%$ & 252 & $57.0 \%$ & 25 & $5.6 \%$ \\
\hline Happiness & 191 & $42.7 \%$ & 240 & $53.7 \%$ & 16 & $3.6 \%$ \\
\hline
\end{tabular}

6.2 Hypothesis 2: A significant positive correlation exists between happiness scores and mindful and gratitude scores among university students.

The following table shows the correlation coefficients between the variables among university students.

Table 4: Correlation coefficients among the variables $(\mathrm{N}=447)$

\begin{tabular}{|c|c|c|c|c|c|c|c|}
\hline Variables & & 1 & 2 & 3 & 4 & 5 & 6 \\
\hline 1. & Mindfulness & - & $0.42^{* *}$ & $0.26^{* *}$ & $0.43^{* *}$ & $0.18^{* *}$ & $0.64^{* *}$ \\
\hline & Gratitude total score & & - & - & - & -- & $0.56^{* *}$ \\
\hline 3. & SOA & & & -- & -- & - & $0.48^{* *}$ \\
\hline 4. & SA & & & & -- & - & $0.44^{* *}$ \\
\hline 5. & $\mathrm{AO}$ & & & & & -- & $0.17^{* *}$ \\
\hline 6. & Happiness & & & & & & -- \\
\hline
\end{tabular}

Table 4 shows a positive significant correlation between the students' scores on the TMS and GRAT (SOA, SA, and AO) and their scores on the OHQ. These correlation coefficients are $0.17,0.44,0.48$, 0.56 , and 0.64 , respectively. There is a significant positive correlation between the TMS scores and the GRAT scores (SOA, SA, and AO). These coefficients are $0.26,0.42,0.18$, and 0.43 (p $\leq 0.01$ ).

6.3 Hypothesis 3: Mindfulness significantly contributes to the prediction of happiness among university students.

To examine this hypothesis, a simple linear regression coefficient was calculated to find the contribution of mindfulness to predicting happiness among university students.

Table 5: A simple regression analysis of predicting the level of happiness among university students

\begin{tabular}{|l|c|c|c|c|c|c|c|c|c|}
\hline Dependent variable & $\begin{array}{c}\text { Independent } \\
\text { variable }\end{array}$ & Contribution & $\begin{array}{c}\text { Regression } \\
\text { coefficient B }\end{array}$ & $\begin{array}{c}\text { Standard } \\
\text { regression } \\
\text { coefficient Beta }\end{array}$ & $\begin{array}{c}\text { Fixed } \\
\text { value }\end{array}$ & F- value & Sig. & t-value & Sig. \\
\hline Happiness $(\mathrm{N}=447)$ & Mindfulness & 0.415 & 1.193 & 0.644 & -3.628 & 315.603 & 0.000 & 14.765 & 0.000 \\
\hline
\end{tabular}

Table (5) shows that mindfulness predicted $41.5 \%$ of the variance in happiness manifestations among university students. This finding shows that the increase in mindfulness levels, the increase in attention, alertness, and mindful awareness of students increases their likelihood of feeling happy. 
6.4 Hypothesis 4: Gratitude significantly contributes to predicting happiness among university students.

A simple linear regression analysis was conducted to examine this hypothesis by calculating the contribution of the GRAT and each one of its domains' total scores to predicting happiness among university students.

Table 6: A simple linear regression analysis of predicting the level of happiness among university students

\begin{tabular}{|l|c|c|c|c|c|c|c|c|c|}
\hline Dependent variable & $\begin{array}{c}\text { Independent } \\
\text { variables }\end{array}$ & Contribution & $\begin{array}{c}\text { Regression } \\
\text { coefficient B }\end{array}$ & $\begin{array}{c}\text { Standard regression } \\
\text { coefficient Beta }\end{array}$ & $\begin{array}{c}\text { Fixed } \\
\text { value }\end{array}$ & F- value & Sig. & t-value & Sig. \\
\hline \multirow{3}{*}{ Happiness $(\mathrm{N}=447)$} & Mindfulness & 0.311 & 1.423 & 0.557 & 23.891 & 200.663 & 0.000 & 5.257 & 0.000 \\
\cline { 2 - 9 } & SOA & 0.234 & 2.001 & 0.484 & 56.297 & 136.188 & 0.000 & 11.670 & 0.000 \\
\cline { 2 - 9 } & $\mathrm{SA}$ & 0.191 & 2.613 & 0.437 & 42.475 & 104.818 & 0.000 & 10.238 & 0.000 \\
\cline { 2 - 9 } & $\mathrm{AO}$ & 0.028 & 0.989 & 0.167 & 67.046 & 12.800 & 0.000 & 3.578 & 0.000 \\
\hline
\end{tabular}

Table (6) shows that the GRAT total score predicted $31.1 \%$ of the variance in happiness among university students. The SOA domain accounted for $23.4 \%$ of the variance in happiness, the SA domain accounted for $19.1 \%$ of the variance in happiness, whereas the AO domain accounted for $2.8 \%$ of the variance in happiness. This finding shows that the increase in gratitude levels (SOA, SA, and AO) among university students increases their likelihood of feeling happy.

6.5 Hypothesis 5: The interaction between mindfulness and gratitude significantly contributes to predicting happiness among university students

To examine this hypothesis, a stepwise multiple regression coefficient was calculated for mindfulness and gratitude in predicting happiness among university students.

Table 7: A stepwise multiple regression analysis of the interaction between mindfulness and gratitude total scores in predicting happiness among university students

\begin{tabular}{|l|l|c|c|c|c|c|c|c|}
\hline Dependent variable & Predictive models & $\mathrm{r}^{2}$-value & $\begin{array}{c}\text { Standard regression } \\
\text { coefficient Beta }\end{array}$ & $\begin{array}{c}\text { Fixed } \\
\text { value }\end{array}$ & f-value & Sig. & t-value & Sig. \\
\hline \multirow{3}{*}{ Happiness ( $=447)$} & Mindfulness + gratitude & 0.515 & $\begin{array}{l}0.498 \\
0.349\end{array}$ & -22.887 & 236.153 & 0.000 & $\begin{array}{c}13.694 \\
9.597\end{array}$ & $\begin{array}{c}0.000 \\
0.000\end{array}$ \\
\cline { 2 - 8 } & \multirow{2}{*}{ Mindfulness + SOA +SA } & 0.544 & 0.492 & & & & 13.562 & 0.000 \\
& & & 0.327 & -19.614 & 176.113 & 0.000 & 9.789 & 0.000 \\
4.400 & 0.000 \\
\hline
\end{tabular}

Table (7) shows that the contribution of the interaction between the mindfulness and gratitude total scores was about $51.5 \%$ of the variance in happiness among university students, whereas the interaction between mindfulness, SOA, and SA was about $54.4 \%$ of the variance in happiness among university students. However, the AO domain's total score did not interact with SOA and SA variables in predicting happiness. This finding shows that the increase in both mindfulness and gratitude among university students increases their likelihood of feeling happy. It indicates the important contribution of the interaction among predictive variables compared to the separate contribution of each variable to predicting happiness. 
6.6 Hypothesis 6: There are fundamental differences in mindfulness and gratitude among university students with high happiness and with low happiness.

To examine this hypothesis, the research sample was divided into two groups according to the OHQ total score median. The first group was students with low happiness, which consisted of students who had a score equal to or less than the median. The other group was students with high happiness which consisted of students who scored higher than the median. The T-test of the statistically significant differences between the two sets was used to identify the differences between the scores of the two groups (students with high happiness and students with low happiness) in terms of the TMS total score, GRAT total score, and the total score of its domains. The following table demonstrates the findings.

Table 8: T-test of the significance of differences between the scores of students with low happiness and students with high happiness

\begin{tabular}{|c|c|c|c|c|c|c|c|c|c|}
\hline Variables & Groups & Number & Mean & SD & t-value & Sig. & $\eta^{2}$ & $\mathrm{D}$ & Effect size ${ }^{* *}$ \\
\hline \multirow{2}{*}{ SOA } & Students with low happiness & 228 & $14 \cdot 31$ & 3.21 & \multirow[b]{2}{*}{9.22} & \multirow[b]{2}{*}{0.000} & \multirow[b]{2}{*}{0.16} & \multirow[b]{2}{*}{0.9} & \multirow[b]{2}{*}{ Large } \\
\hline & Students with high happiness & 219 & 17.17 & 3.36 & & & & & \\
\hline \multirow{2}{*}{ SA } & Students with low happiness & 228 & $16.5^{2}$ & 2.55 & \multirow[b]{2}{*}{$7 \cdot 39$} & \multirow{2}{*}{0.000} & \multirow[b]{2}{*}{0.11} & \multirow[b]{2}{*}{0.7} & \multirow[b]{2}{*}{ Medium } \\
\hline & Students with high happiness & 219 & 18.15 & 2.09 & & & & & \\
\hline \multirow{2}{*}{$\mathrm{AO}$} & Students with low happiness & 228 & 11.49 & 2.38 & \multirow{2}{*}{2.88} & \multirow{2}{*}{0.004} & \multirow[b]{2}{*}{0.02} & \multirow[b]{2}{*}{0.3} & \multirow[b]{2}{*}{ Small } \\
\hline & Students with high happiness & 219 & 12.17 & 2.59 & & & & & \\
\hline \multirow{2}{*}{ GRAT total score } & Students with low happiness & 228 & 42.32 & 5.25 & \multirow{2}{*}{10.52} & \multirow{2}{*}{0.000} & \multirow[b]{2}{*}{0.19} & \multirow[b]{2}{*}{0.9} & \multirow[b]{2}{*}{ Large } \\
\hline & Students with high happiness & 219 & 47.49 & 5.14 & & & & & \\
\hline \multirow{2}{*}{ TMS total score } & Students with low happiness & 228 & 72.61 & 7.17 & \multirow[b]{2}{*}{12.30} & \multirow{2}{*}{0.000} & \multirow[b]{2}{*}{0.25} & \multirow[b]{2}{*}{1.16} & \multirow[b]{2}{*}{ Large } \\
\hline & Students with high happiness & 219 & 80.66 & 6.63 & & & & & \\
\hline
\end{tabular}

Table 8 shows that the t-value is significant at the level of o.o1 in the domains of SOA, SA, and AO, as well as the GRAT total score (large effect size of these differences), and the TMS total score (large effect size of these differences). Thus, significant differences exist between the scores of students with low happiness and students with high happiness in the GRAT domains, the GRAT total score, and the TMS total score. These differences were in favor of students with high happiness.

\section{Discussion}

In this section, the findings are discussed in the light of the findings of previous studies. The results related to hypothesis 1 , as shown in table 3 , revealed that mindfulness was moderate in $58.9 \%$ of the research sample, and the level of gratitude was moderate to high in $49.9 \%$ and $49.7 \%$, respectively. The SOA domain was moderate, the SA was high, and the AO was moderate. Additionally, happiness was of moderate to a high level in $53.7 \%$ and $42.7 \%$ of the research sample, respectively.

This result indicates that the Princess Nourah Bint Abdulrahman University students have a moderate level of mindfulness and a moderate to a high level of gratitude and happiness. The moderate level of mindfulness among students can be explained by the developmental phase of the students as they identify their role and lifestyle, look forward to becoming adults, and enhance their insight of the self and the surrounding world. This is what Eriksson calls productivity (Al Harthy, 2019). This finding is consistent with the study of Hj Ramli, Alavi, Mehrinezhad, and Ahmadi (2018), which found a moderate level of mindfulness among the participants aged 18-30 years. However, it differs from the findings of Al Shlwey (2018) that showed high mindfulness among university students.

The moderate to high levels of gratitude and happiness can be explained by the educational, social, or health services the students enjoy in the university setting. This finding is consistent with what Al-Rabee and Ababneh (2018) pointed out that the individual's acknowledgment of others' contribution to his/her well-being made the individual feel a high level of gratitude, which leads to 
happiness, and reflected their positive emotions. This finding indicates that students received benefits. It is also an indicator of their good intentions toward their environment. Students in the undergraduate stage also feel positive about their achievements and aspirations (Shawaqfeh and Almahaireh, 2019). This result is also consistent with Shawaqfeh and Almahaireh's study (2019) that found a moderate level of happiness closer to high among university students.

According to table 4, the results of hypothesis 2 showed a significant positive correlation between the gratitude and mindfulness scores and happiness scores of students. This means that the higher gratitude and mindfulness, the higher the students' happiness scores become. The significant positive relationship between the mindfulness scores and happiness scores among university students can be explained in terms of what the results revealed that mindfulness is related to psychological adaptation variables. It was found that self-compassion was a determinant factor in the relationship between mindfulness and happiness (Hollis-Walker and Colosimo, 2011). Additionally, mindfulness training resulted in an improvement in happiness average scores and average blood sugar levels (Fakhri et al., 2017).

Furthermore, the significant positive relationship between the gratitude scores (SOA, SA, and $\mathrm{AO}$ ) and happiness scores among university students can be explained by two experiments which showed that grateful thinking improves the mood and the results supported the validity of the gratitude test's predictive ability of happiness (Watkins et al., 2003). The grateful recalling state stimulated large increases in the state of hope and happiness. That study recommended grateful recalling as a practice that can enhance present happiness and hope in the future (Witvilet et al., 2019). Simons et al. (2020) also found that SOA only was largely correlated with positive instant experiences (positive correlation) in daily life.

This result can also be explained according to the broaden-and-build theory, which pointed out that positive emotions can broaden individuals' thinking and allow them to build psychological, intellectual, and social resources. Additionally, positive emotions, especially gratitude, may play a role in motivating individuals to engage in positive behaviors that lead to their improvement (Armenta et al., 2017; Froh, Yurkewiczb, and Kashdan, 2009).

This result is also consistent with the findings of Kavaklı, Özteke Kozan, Kesici, and Ak (2019) and Abid (2017) that a significant positive association exists between happiness, mindfulness, and forgiveness. Moreover, hierarchical regression analysis showed that forgiveness and mindfulness predicted happiness. Bagheri and Gharehbaghi (2019) found a positive correlation between mindfulness, happiness, and healthy development. This result is also consistent with Sapmaz, Yıldırım, Topçuoğlu, Nalbant, and Sızır (2016) and Kausar (2018) who found a significant positive correlation between gratitude and happiness. Alarcón and Caycho Rodríguez (2015) also found that the factors of gratitude, reciprocal treatment, and moral obligation had a positive association with happiness, and the factors of positive feelings toward life, life satisfaction, and personal devotion had a positive correlation to happiness.

As shown in table 5, the results of hypothesis 3 revealed the significant contribution of mindfulness to predicting happiness among university students. Mindfulness predicted $41.5 \%$ of the variance in happiness manifestations among university students. This result indicates that higher mindfulness levels and the increase in students' attention, alertness, and mindful awareness increases the likelihood of feeling happy.

This finding is consistent with the study of Campos et al. (2016) that found two facets of mindfulness (observing and awareness) and two aspects of self-compassion (self-kindness and common humanity) were the highest predictors of happiness. Their results also revealed the mediating role of an indirect effect of observing, awareness, self-kindness, and common humanity in the relationship between meditation and happiness. They supported the mindfulness model and selfcompassion facets as mediators in the meditation-happiness relationship.

Previous studies and interpreting models of mindfulness emphasized cognitive, attention, and behavioral flexibility as components and consequences of mindfulness. The opposite pattern of adopting a narrow perspective and automatic responses, which are mostly habitual and inflexible, is 
often associated with poor problem solving and higher distress (Basha, 2018). The present results are also consistent with the results of Chavan, Deshmukh, and Singh (2017) that pointed out gratitude and mindfulness as two of the highest predictors of happiness, as gratitude contributed $36 \%$ and mindfulness contributed $13 \%$ in predicting happiness.

With respect to hypothesis 4 , as shown in table 6 , gratitude significantly contributed to predicting happiness among university students. Grateful persons were found to have a sense of abundance, appreciate the contributions of others to the quality of their life, and have a predisposition to appreciate the simple pleasures of life. They also appreciate the importance of expressing gratitude (Thomas and Watkins, 2003), which makes them happier.

In this regard, Chavan et al. (2017) found out that gratitude and mindfulness were two of the highest predictors of happiness as gratitude contributed $36 \%$ and mindfulness contributed $13 \%$ to predicting happiness. Additionally, gratitude significantly contributed to predicting life satisfaction by $27 \%$ (Ibrahim, 2019). Trait gratitude was also found to exceed forgiveness, patience, and self-control in predicting trait hope and happiness (Witvliet, Richie, Luna, and Van Tongeren, 2019). Furthermore, gratitude had a significant contribution to predicting happiness by $18 \%$ (Sapmaz et al., 2016). In the study of Kardas Cam, Eskisu, and Gelibolu (2019), gratitude only predicted $36 \%$ of the variance in wellbeing and was one of the highest predictors of well-being.

The results of hypothesis 5 showed the contribution of the interaction between the research variables in predicting happiness among university students, as follows:

- The interaction between mindfulness and gratitude total scores contributed almost $51.5 \%$ of the variance in happiness among university students,

- The interaction between mindfulness and SOA and SA contributed almost $54.4 \%$ of the variance in happiness among university students; but

- The total score of the AO domain did not interact with SOA and SA variables in predicting happiness.

This finding shows that higher levels of both mindfulness and gratitude among university students increase the likelihood of feeling happy.

The relationships between each of the predictors (mindfulness, gratitude, SOA, SA, and AO) and happiness among university students, the interpretation of these relationships, and the previous studies supporting the current findings were mentioned above. The results of the interaction among predictors correspond with the complex nature of human behavior, and they offer a more comprehensive understanding of the factors affecting this behavior. Consequently, the results of interaction among the present research variables provide a more comprehensive understanding of happiness among university students.

In the light of the simple linear regression results for each predictor in predicting happiness among university students, the results of the stepwise multiple regression analysis among these variables, and the reviewed literature and theoretical frameworks related to the research variables, the authors developed a theoretical conceptualization of the relationships among the research predictors (mindfulness, gratitude, SOA, and SA) and happiness (criterion variable) among university students. The study proposes a theoretical model that mindfulness affects happiness cognitively, whereas gratitude affects happiness emotionally. The findings of the study and the relevant literature point out that mindfulness and gratitude are associated with a high level of happiness, and they significantly contribute to predicting happiness among university students. When comparing students with high happiness and students with low happiness, it was found that students with high happiness had higher mindfulness, gratitude, SOA, SA, and AO. 


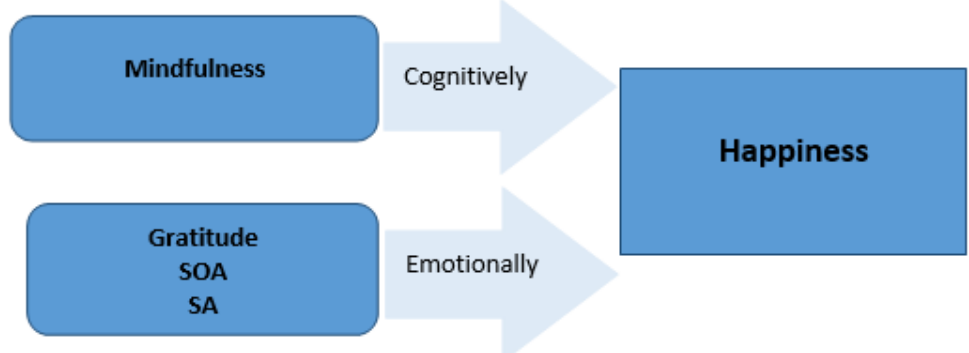

Figure 1: The proposed theoretical model

The results of hypothesis 6 found significant differences between the mean scores of students with low happiness and students with high happiness in mindfulness in favor of students with high happiness. Significant differences were also found between the mean scores of students with low happiness and students with high happiness in gratitude in favor of students with high happiness. In this regard, it can be said that mindfulness led to an increase in emotion regulation, a decline in emotional fatigue, and an increase in functional satisfaction (De la Fuente, Mañas, Franco, Cangas, and Soriano, 2018). Dispositional and state mindfulness also predicted self-regulated behavior and positive emotional states (Brown and Ryan, 2003). Therefore, students with high happiness had higher mindfulness compared to students with low happiness.

Gratitude has benefits on the societal level, such as mutual altruism and social cohesion. On the individual level, gratitude enhances personal well-being and personal relations. Recent literature reveals causal links between gratitude and one's well-being (Yüksel and Oğuz Duran, 2012). Gratitude is a positive act linked to well-being as results confirmed the association between gratitude and personal well-being (Lin, 2015). Grateful states result from the acknowledgment that (a) the person received a positive result; (b) there is an external source for this positive result; (c) the benevolent made an effort to provide them with the benefit. Therefore, gratitude is an empathic emotion (Froh et al., 2009) that leads to feelings of happiness.

\section{Conclusion}

The findings of the present study answered its main questions. The statistical analyses revealed that gratitude had a significant contribution of $31 \%$ and mindfulness had a significant contribution of $41.5 \%$ to predicting happiness among university students. Additionally, the interaction between the total scores of mindfulness and gratitude contributed $51.5 \%$ of the variance in happiness among university students, and the interaction between mindfulness, SOA, and SA contributed $54.5 \%$ of the variance in happiness among university students. However, the total score of the AO domain did not interact with the variables of SOA and SA in predicting happiness. The study also found a positive correlation between mindfulness, gratitude (SOA, SA, and $\mathrm{AO}$ ), and happiness. It revealed that Princess Nourah Bint Abdulrahman University students had moderate levels of mindfulness and moderate to high levels of gratitude and happiness. The SOA domain was moderate, SA was high, and AO was moderate. Students with high happiness were higher in mindfulness, gratitude, SOA, SA, and AO compared to students with low happiness.

\section{Recommendations}

Based on the results of the present study, the following recommendations are made:

- Gratitude can improve students' happiness.

- Therapeutic interventions based on gratitude can be used efficiently to improve the level of 
happiness.

- More research about the predictors of happiness among university students and the interaction among these factors should be conducted as the attainment of happiness has great importance in an individual's life.

- Preventive programs should be offered to adults where mindfulness is developed as a means to reduce suffering and enhance happiness.

- The pathways that link Alexithymia, mindfulness, gratitude, and psychological well-being should be investigated.

- The proposed model about the association between mindfulness (cognitively) and gratitude (emotionally) and their role in attaining individuals' happiness for the various age groups should be verified.

- Programs should be developed for university students to target developing their cognitive, attentional, and behavioral flexibility as components and consequences of mindfulness to increase their ability to effectively manage complicated challenges and competitive requirements of university life.

\section{Acknowledgement}

This research was funded by the Deanship of Scientific Research at Princess Nourah bint Abdulrahman University through the Fast-track Research Funding Program.

\section{References}

Abid, M. (2017). Examining the predictive role of mindfulness in forgiveness and happiness among psychiatric patients. Journal of Psychology and Behavioral Sciences, 2(2), 163-176. DOI: 10.32879/pjpbs.2016.2.2.163-176

AlAbdaely, A. (2018). Positive psychology (in Arabic). Riyadh: Dar Alzahraa.

Alarcón, R., \& Caycho Rodríguez, T. (2015). Relations Between Gratitude and 11. Happiness among university students of Metropolitan Lima. Psychologia, 9(1), 59-69.

Al-Enzi, F. (2001). Feeling happy and its relationship to some personal traits: A comparative study between males and females (in Arabic). Journal of Psychological Studies, 11(3), 351-377.

$\mathrm{Al}$ Harthy, S. (2019). Mindfulness and its relationship to symptoms of anxiety among the students of the Technical College of Bisha Governorate (in Arabic). Sohag Journal of Education, (57), 130-157.

Al-Rabee, F. and Ababneh, K. (2018). Gratitude and quality of life among Yarmouk University students in the light of some variables (in Arabic). Educational Science Studies, 45(4), 653-672.

Al Shlwey, A. (2018). Mindfulness and its relationship to self-efficacy in a sample of Faculty of Education Students at AL-Dawadmi (in Arabic). Journal of Scientific Research in Education, (19), 1-24.

Armenta, C., Fritz, M., \& Lyubomirsky, S. (2017). Functions of positive emotions: Gratitude as a motivator of selfimprovement and positive change. Emotion Review, 9(3), 183 - 190. doi: 10.1177/1754073916669596.

Bagheri, F. \& Gharehbaghi, F. (2019). The relationship between mindfulness, happiness and healthy lifestyle. Caspian Journal of Health Research, 4(2), 44-48. DOI:https://doajorg.sdl.idm.oclc.org/article/bbbf670641854bfcaiczdcfbfciafbc9

Basha, S. (2018). The moderating role of Alexithymia and mindfulness in the relationship between interpersonal problems and borderline personality disorder symptoms in a non-clinical sample (in Arabic). Annals of the Psychological Research Center, 14(6), 1-83.

Basha, S., and AbdAlstar, R. (2015). Positive psychology: A contemporary vision (in Arabic). Cairo: The AngloEgyptian Bookshop.

Bellin, Z. (2015). The meaning connection between mindfulness and happiness. The Journal of Humanistic Counselling, 54(3), 221-235. DOI: https://doi.org/10.1002/johc.12013.

Brown, W. and Ryan, R. (2003). The benefits of being present: Mindfulness and its role in psychological well-being. Journal of Personality and Social Psychology, 84(4), 822-848. DOI: https://psycnet.apa.org/buy/2003-02410-012.

Campos, D., Cebolla, A., Quero, S.,Bretón-López, J., Botella, C., Soler, J., García-Campayo, J., Demarzo, M., \& Baños, R. (2016). Meditation and happiness: Mindfulness and self-compassion may mediate the meditationhappiness relationship. Personality and Individual Differences, (93), 8o-85. DOI: https://doiorg.sdl.idm.oclc.org/10.1016/j.paid.2015.08.040. 
Chavan, S., Deshmukh, J. \& Singh, B. (2017). Role of mindfulness, belief in personal control, gratitude on happiness among college students. Indian Journal of Health and Well-being, 8(10), 1184-1186.

Csikszentmihalyi, M., and Hunter, J. (2003). Happiness in everyday life: The uses of experience sampling. Journal of Happiness Studies, 4, 185-199. Doi: https://doi.org/10.1023/A:1024409732742.

Dekeyser, M., Raes, F., Leijssen, M., Leysen, S., and Dewulf, D. (2008). Mindfulness skills and interpersonal behaviour. Personality and Individual Differences, 44(5), 1235-1245. DOI: 10.1016/j.paid.2007.11.018.

De la Fuente, J., Mañas, I., Franco, C., Cangas, A., and Soriano, E. (2018). Differential effect of level of self-regulation and mindfulness training on coping strategies used by university students. International Journal of Environmental Research and Public Health, 15(10), 2230.DOI: https://doi.org/10.339o/ijerph15102230.

Diener, E., Suh, E., Lucas, R. \& Smith, H. (1999). Subjective well-being: Three decades of progress. Psychological Bulletin, 125(2), 276-302.

Duprey, E., McKee, L., O'Neal, C., \& Algoe, S. (2018). Stressful life events and internalizing symptoms in emerging adults: The roles of mindfulness and gratitude. Mental Health $\mathcal{E}$ Prevention, 12, 1-9. DOI: https://doi.org/10.1016/j.mhp.2018.08.003.

Fakhri, M., Bahar, A., \& Amini, F. (2017). Effectiveness of mindfulness on happiness and blood sugar level in diabetic patients. Journal of Mazandaran University of Medical Sciences, 27(151), 94-104. DOI: http://jmums.mazums.ac.ir/article-1-7846-en.html.

Feldman, G., Hayes, A., Kumar, S., Greeson, J., and Laurenceau, J. (2007). Mindfulness and emotion regulation: The development and initial validation of the Cognitive and Affective Mindfulness Scale-Revised (CAMS-R). Journal of Psychopathology and Behavioral Assessment, 29(3), 177-190. DOI: 10.1007/s10862-006-9035-8.

Froh, J., Fan, J., Emmons, R., Bono, G., Huebner, E., \& Watkins, P. (2011). Measuring gratitude in youth: Assessing the psychometric properties of adult gratitude scales in children and adolescents. Psychological Assessment, 23(2), 311-324. DOi: https://psycnet.apa.org/doi/10.1037/aoo2159o.

Froh, J., Yurkewiczb, C., and Kashdan, T. (2009). Gratitude and subjective well-being in early adolescence: Examining gender differences. Journal of Adolescence, 32(3), 633-650. DOI: https://doi.org/10.1016/j.adolescence.2008.06.oo6.

Fuller-Tyszkiewicz, M., Richardson, B., Lewis, V., Linardon, J., Mills, J., Juknaitis, K., Lewis, C., Coulson, K., O'Donnell, R., Arulkadacham, L., Ware, A. \& Krug, I. (2019). A randomized trial exploring mindfulness and gratitude exercises as eHealth-based micro-interventions for improving body satisfaction. Computers in Human Behavior, 95, 58-65. DOI:https://doi.org/10.1016/j.chb.2019.01.028.

Geher, G., \& Wedberg, N. (2019). Happiness, gratitude, and love. In G., Geher, \& N., Wedberg, (ed.), Positive Evolutionary Psychology: Darwin's Guide to Living a Richer Life. New York: Oxford University Press. DOI:10.1093/oso/9780190647124.003.00o6

Gilbert, P., McEwan, K., Gibbons, L., Chotai, S., Duarte, J. \& Matos, M. (2012). Fears of compassion and happiness in relation to alexithymia, mindfulness, and self-criticism. Psychology and Psychotherapy: Theory and Practice, 85(4), 374-39o. DOI: https://doi.org/10.1111/j.2044-8341.2011.02046.x.

Hj Ramli, N., Alavi, M., Mehrinezhad, S. \& Ahmadi, A. (2018). Academic stress and self-regulation among university students in Malaysia: Mediator role of mindfulness. Behavioral Sciences, 8(1), 12. DOI: https://doi.org/10.339o/bs8o10o12.

Hollis-Walker, L. \& Colosimo, K. (2011). Mindfulness, self-compassion, and happiness in non-meditators: A theoretical and empirical examination. Personality and Individual Differences, 50(2), 222-227. DOI: https://doi.org/10.1016/j.paid.2010.09.033.

Ibrahim, R. (2019). The relative contribution of both gratitude and forgiveness to the prediction of life satisfaction of university students (in Arabic). Journal of Scientific Research in Education, 13(20), 367- 398.

Jan, N. (2008). The relationships between happiness and religious faith, social support, marital satisfaction economic status, and physical health. Psychological Studies, 18(4), 601-648.

Kardas, F., Cam, Z., Eskisu, M., and Gelibolu, S. (2019). Gratitude, hope, optimism and life satisfaction as predictors of psychological well-being. Eurasian Journal of Educational Research, 82, 81-10o. DOI: 10.14689/ejer.2019.82.5.

Kausar, R. (2018). Relationship between gratitude and happiness in college students. Indian Journal of Positive Psychology, 9(1), 109-113. DOI: https://doi.org/10.15614/ijpp.vgio1.11752.

Kavaklı, M., Özteke Kozan, H., Kesici, Ş., \& Ak, M. (2019). How can we feel happy? The examination of relationships among happiness, mindfulness and forgiveness. Bülent DİLMAÇ, 3(2), 198-208.

Leary, K. (2015). The effects of two novel gratitude and mindfulness interventions on well-being. The Journal of Alternative and Complementary Medicine, 21(4), 1-3. DOI: https://doi.org/10.1089/acm.2014.0119.

Lin, C. (2015). Self-esteem mediates the relationship between dispositional gratitude and well-being. Personality and Individual Differences, (85), 145-148. DOI: https://doi.org/10.1016/j.paid.2015.04.045. 
McCullough, M., Kilpatrick, S., Emmons, R., \& Larson, D. (2001). Is gratitude a moral affect? Psychological Bulletin, 127(2), 249-266. DOI: https://psycnet.apa.org/buy/2001-16969-004.

Peterson, C., Ruch, W., Beermann, U., Park, N. \& Seligman, M. (2007). Strengths of character, orientations to happiness, and life satisfaction. The Journal of Positive Psychology, 2(3), 149-156. DOI: https://doi.org/10.1080/17439760701228938.

@PNU_Live. (2020, 7 5). @PNU_Live. $\quad$ Retrieved $7 \quad$ 2020, from Teitter: https://twitter.com/pnu_live/status/1279758255531659264

Przepiorka, A., \& Sobol-Kwapinska, M. (2020). People with positive time perspective are more grateful and happier. Journal of Happiness Studies. DOI:https://doi.org/10.1007/s10902-020-00221-z.

Ryan, R., and Deci, E. (2001). On happiness and human potentials: A review of research on hedonic and eudaimonic well-being. Annual Review of Psychology, 52, 141-166. Doi: https://doi.org/10.1146/annurev.psych.52.1.141.

Safaria, T. (2014). Forgiveness, gratitude, and happiness among college students. International Journal of Public Health Science (IJPHS), 3(4), 241-245.

Sapmaz, F., Yıldırım, M., Topçuoğlu, P., Nalbant, D., \& Sızır, U. (2016). Gratitude, forgiveness and humility as predictors of subjective well-being among university students. International Online Journal of Educational Sciences, 8(1), 38-47. DOI: http://dx.doi.org/10.15345/iojes.2016.01.004.

Seligman, M., Steen, T., Park, N., and Peterson, C. (2005). Positive psychology progress: empirical validation of interventions. American Psychologist, 6o(5), 410-421. Doi: https://doi.apa.org/doi/10.1037/ooo3-066X.60.5.410.

Shawaqfeh, B. \& Almahaireh, A. (2019). Technowellness and its relationship with happiness and optimism among the University of Jordan students. Journal of Social Studies Education Research, 10(2), 145-167.

Simons, M., Lataster, J., Peeters, S., Reijnders, J., Janssens, M., and Jacobs, N. (2020). Sense of abundance is associated with momentary positive and negative affect: an experience sampling study of trait gratitude in daily life. Journal of Happiness Studies, 21, 2229-2236. DOI: https://doi.org/10.1007/s10902-019-0o181-z.

Swain, N., Lennox Thompson, B., Gallagher, S., Paddison, J., \& Mercer, S. (2020). Gratitude Enhanced Mindfulness (GEM): A pilot study of an internet-delivered programme for self-management of pain and disability in people with arthritis. The Journal of Positive Psychology, 15(3), 420-426. DOI:10.1080/17439760.2019.1627397.

Swickert, R., Bailey, E., Hittner, J., Spector, A., Benson-Townsend, B. \& Silver, N. (2019). The mediational roles of gratitude and perceived support in explaining the relationship between mindfulness and mood. Journal of Happiness Studies, 20, 815-828. DOI: https://doi.org/10.1007/s10902-017-9952-o.

Thomas M. and Watkins P. (2003). Measuring the grateful trait: Development of revised GRAT. Poster session at the Annual Convention of the Western Psychological Association, Vancouver, Canada: British Columbia.

Watkins, C., Woodward, K., Stone, T., and Kolts, R. (2003). Gratitude and happiness: Development of a measure of gratitude, and relationships with subjective well-being. Social Behavior and Personality, 31(5), 431-451, https://doi.org/10.2224/sbp.2003.31.5.431.

Witvliet, C., Richie, F., Luna, L., and Van Tongeren, D. (2019). Gratitude predicts hope and happiness: A two-study assessment of traits and states. The Journal of Positive, 14(3), 271-282. DOI: 10.1080/17439760.2018.1424924.

Yüksel, A. and Oğuz Duran, N. (2012). Turkish adaptation of the gratitude questionnaire. Eurasian Journal of Educational Research, (46), 199-216. 